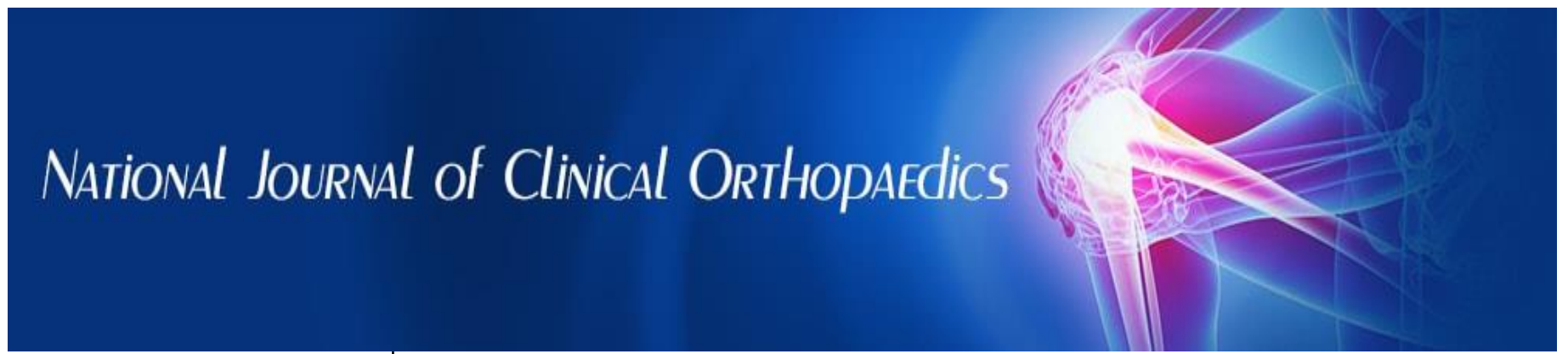

ISSN (P): 2521-3466

ISSN (E): 2521-3474

(C) Clinical Orthopaedics

www.orthoresearchjournal.com

2019; 3(1): 147-153

Received: 21-11-2018

Accepted: 25-12-2018

\section{Dr. Madhukar}

Associate Professor, Department of Orthopaedics Sree Balaji

Medical College and Hospital,

No. 7, Works Road, New Colony,

Chromepet, Chennai, Tamil

Nadu, India

\section{Dr. Vinoth KR}

MS Ortho Postgraduate Junior

Resident, Department of

Orthopaedics Sree Balaji Medical

College and Hospital, No. 7,

Works Road, New Colony,

Chromepet, Chennai, Tamil

Nadu, India

Dr. Vijay Narasimman Reddy Professor and Head Department of Orthopaedics Sree Balaji Medical College and Hospital, No. 7, Works Road, New Colony, Chromepet, Chennai, Tamil Nadu, India.

\section{Correspondence}

Dr. Madhukar

Associate Professor, Department of Orthopaedics Sree Balaji Medical College and Hospital, No. 7, Works Road, New Colony, Chromepet, Chennai, Tamil

Nadu, India

\section{Prospective comparative study of short term functional outcomes of radial head excision arthroplasty and radial head replacement arthroplasty in radial head fracture}

\author{
Dr. Madhukar, Dr. Vinoth KR and Dr. Vijay Narasimman Reddy
}

DOI: https://doi.org/10.33545/orthor.2019.v3.i1c.29

\section{Abstract}

The radial head is essential for the rotational stability of the forearm and resistance to valgus stress. Radial head fractures are the most common elbow fracture in adults, constituting approximately one third of all elbow fracture. Primary goal in surgical treatment is to restore elbow stability in order to preserve the complex physiologic elbow kinematics. Our study is to compare functional outcome between excision arthroplasty and replacement arthroplasty and we found no difference between functional outcomes in short term between the two modalities of treatment.

Keywords: Radial head fracture, metal prosthesis, radial head excision arthroplasty.

\section{Introduction}

Radial head fracture is the most common fracture involving the elbow, constituting approximately one third of all elbow fracture. These fractures typically occur when an axial load is applied to the forearm, causing the radial head to hit the capitellum of the humerus. The severity of these injuries runs the gamut from minimally displaced fractures needing minimal treatment to those with major displacement or comminution, requiring surgical fixation, excision, or replacement ${ }^{[1]}$. Radial head fractures are common injuries, occurring in about $20 \%$ of all acute elbow injuries ${ }^{[2]}$. Radial head fractures are more frequent in women than in men, and are more likely to happen in people who are between 30 and 40 years of age ${ }^{[3]}$. Radial head fractures were classified on the basis of their severity by Mason in $1954{ }^{[4]}$. He described four types of radial head fractures ${ }^{[4]}$.

Mason Type I included fractures which were undisplaced or minimally displaced.

Mason Type II included fractures with displacement, depression or angulation.

Mason Type III included comminuted fractures, and

Mason Type IV included fractures with comminution and elbow dislocation. (Figure 1)

Mason type III and IV are commonly associated with other injures of the elbow as capitellum fractures and coronoid fractures and/or ligaments disruption, both medial and lateral ligaments disruption and interosseous membrane disruption ${ }^{[5-8]}$. 


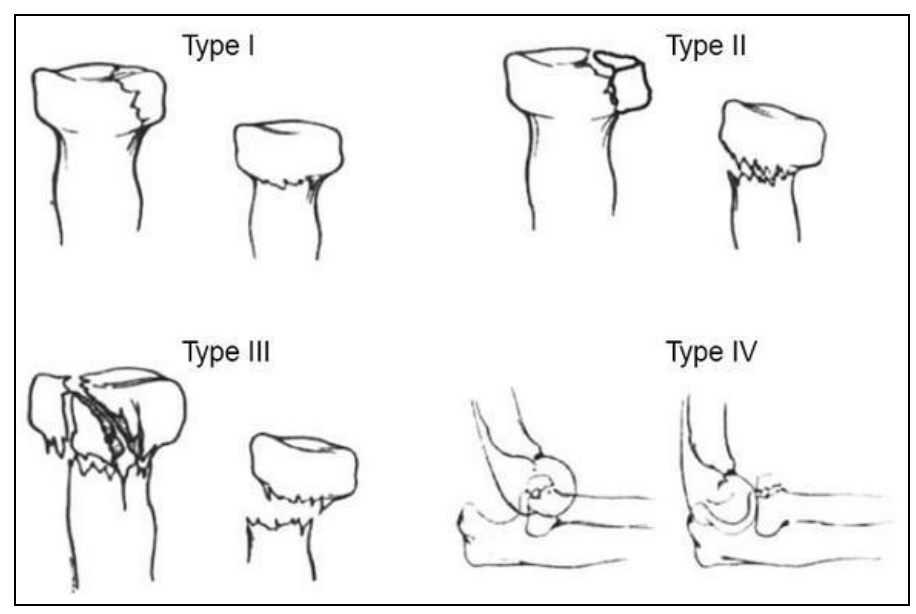

Fig 1: Mason classification of radial head fractures

The important role of the radial head in the elbow joint and stability of the forearm have aroused greater attention. Radial head has two primary functions

1. The radial head is a secondary valgus stabilizer of the joint and it is involved in transmission of axial force load through the elbow during flexion ${ }^{[9]}$.

2. It is also a varus and external rotatory constrainer ${ }^{[10]}$

Fractures of radial head are treated by different methods depending on the pattern and severity of injury which includes conservative treatment, excision arthroplasty, open reduction and internal fixation (ORIF) and replacement arthroplasty.

Traditionally excision arthroplasty has been the modality of treatment for Mason Type III and in certain Mason Type II fractures. However, there were complications because of the excision which includes Chronic ulnar wrist pain, Instability, Elbow stiffness, Loss of strength, Degenerative arthritis Cubitus valgus, Heterotopic calcification and Myositis ossificans. Some of these complications are because of the loss of biomechanics in elbow due to excision of radial head which has important stabilising functions stated above.

In order to reduce the complications open reduction and internal fixation (ORIF) and replacement arthroplasty were thought to improve the functional outcome and reduce complications due to mechanical disadvantage of radial head excision. However various studies have shown that all methods are equally good and have similar outcomes.

We conducted a prospective study to compare short term functional outcome between radial head excision arthroplasty and replacement arthroplasty.

\section{Material and methods}

2.1 Aim of the study: Our aim is to compare clinical, radiological and short term functional outcome of radial head excision arthroplasty versus radial head replacement arthroplasty in the treatment for the management of radial head fractures. This is a comparative study of radial head fracture reporting at the Department of Orthopaedics at Sree Balaji Medical and Hospital, Chromepet from June 2016 to January 2019. Recruitment of cases stopped in January 2018, so that the follow up times is for a minimum period of 1 year. Hence the study lasted 2 years and 8 months, while the recruitment of patients was for 1 year 6 months.

\subsection{Inclusion criteria}

- Both men and women in age group of more than 20years who are medically fit for surgery

- $\quad$ Radial head fractures Mason Type II and Type III
- Patients who are willing to give consent

\subsection{Exclusion criteria}

- Patients not fulfilling the above inclusion criteria were excluded.

- Compound fractures

- Malunited fractures

- Complicated fractures

- Pathological fractures due to malignancy

- Periprosthetic fractures

- Paediatric fractures (before physeal closure).

- Fractures associated with polytrauma

- Patient associated with elbow osteoarthritis, neurovascular injuries were excluded from the study

\subsection{Pre-operative protocol:}

All the patients were received in the casualty department and orthopaedic department in Sree Balaji medical college and hospital and primary treatment was given to them. If there were any other major associated injuries, they were treated accordingly at first. After the general condition of the patient improved, X-ray of elbow - AP View and lateral view were taken. If required addition of oblique views were taken to see critical in identifying and characterizing the fracture and associated injuries. The fractures were reduced in closed manner by supination - flexion technique and an above elbow slab was applied. Post reduction Check X-rays were taken to know the fracture pattern.

Computed tomography (CT) is particularly useful to better characterize fractures of the elbow. The complexity of the elbow joint limits the ability of plain radiography to detect subtle fractures. Computed tomography is helpful to quantify displacement, and it allows a better assessment of the reparability of the fracture fragments ${ }^{[11]}$.

Magnetic resonance imaging (MRI) can provide more information regarding associated soft tissue injuries of the collateral ligaments, and the interosseous membrane of the forearm. Other injuries that can be identified with magnetic resonance imaging include chondral contusion, osseous edema, and non-ossified loose bodies ${ }^{[11]}$.

The patients were explained in detail regarding the advantages and complications of both the techniques taking into consideration, the nature of injury, degree of comminution, financial status of the patients, day to day activities of the patient and professional status. Patients were allocated to excision arthroplasty or replacement arthroplasty.

\subsection{Implant design}

The patients in the radial head replacement group were treated with titanium radial head prostheses

\subsection{Operative Procedure}

\subsubsection{Intra operative protocol:}

Preoperative antibiotics were started half hours before the surgery after attaining medical fitness. The patient was positioned supine on the fluoroscopic table with elbow in 90 degree flexion and internal rotation of arm and mid pronation of elbow under general anesthesia or regional block. We routinely used tourniquet during surgery. Surgical exposure for both the techniques employed a Kocher's approach to the radial head, the interval between extensor carpi ulnaris and anconeus muscle was made. 
2.6.2 Operative procedure - Radial head excision arthroplasty The radial head exposed from lateral side of elbow. We always used Kocher's approach for exposing the radial head. The cleavage between anconeus and extensor carpi ulnaris was developed. The LCL was retracted medially along with ECU. Incise the annular ligament in the midlateral plane to avoid injury to lateral ulnar collateral ligament (LUCL). Fracture fragment should be identified and removed with nimbler check under $\mathrm{C}$-arm to avoid missing of fragments. Thorough wash of both wounds done. The LCL and annular ligament were repaired after that subcutaneous and skin closure was done. Compression bandage was applied. Tourniquet was released and an above elbow slab was applied with forearm in supination after giving traction to reduce distal radioulnar joint and slab continued for 3 weeks.

\subsubsection{Operative procedure - Radial head replacement}

The radial head exposed from lateral side of elbow. We always used Kocher's approach for exposing the radial head. The cleavage between anconeus and extensor carpi ulnaris was developed. A medulla dilation drill was used to enlarge the medulla until the intra-medullary bone cortex was reached. The excised radial head fragments are put together to size the radial head. The prostheses were tried from the small size to the large until the right size was determined. Also, clinical and radiological examinations were undertaken to confirm the stability of the elbow joint and the neck and the suitability of the prostheses. After replacement, the annular ligaments were sutured, but not too tight in order not to affect the supination of the forearm. Collateral ulnar ligament complex injuries were fixed and reconstructed operatively. After that subcutaneous and skin closure was done. Compression bandage was applied. Tourniquet was released and an above elbow slab was applied.

\subsection{Post-operative management: \\ 2.7.1.1 Radial head excision:}

The upper limb was kept elevated. Wound inspection was done on $2^{\text {nd }}$ POD. Intravenous antibiotics were maintained till $3^{\text {rd }}$ POD and then switched over to oral antibiotics till $6^{\text {th }}$ POD. Suture removal was done on $10^{\text {th }}$ POD, and above elbow slab was applied. After $4^{\text {th }}$ weeks the slab was removed, after obtaining check $\mathrm{X}$ rays. Active elbow mobilization exercises were started at the end of $4^{\text {th }}$ week. By the end of $6^{\text {th }}$ weeks, active pronation and supination exercises were started.

\subsubsection{Radial head replacement}

\section{Zero To six weeks (Early ROM \& Protect Repair):}

Wound inspection was done on $2^{\text {nd }}$ POD. Intravenous antibiotics were maintained till $3^{\text {rd }}$ POD and then switched over to oral antibiotics till $6^{\text {th }}$ POD. Hinged Elbow Brace worn at all times (after the initial dressing removed). Suture removal was done on $10^{\text {th }}$ POD. Avoid varus/valgus forces across the elbow until 3 months postop. Initiate elbow exercise program 5 times per day: Passive and active elbow ROM to full flexion, Elbow extension to $20^{\circ}$ (with forearm pronated) at $2^{\text {nd }}$ week, Elbow extension to $10^{\circ}$ (with forearm pronated) at $3^{\text {rd }}$ week, Elbow extension to $0^{\circ}$ (with forearm pronated) at $4^{\text {th }}$ week, Forearm pronation/supination ROM with elbow at $90^{\circ}$ flexion, Grip and wrist/hand AROM immediately, Perform supination ROM only with the elbow flexed to 90 degrees.

\section{More than 6 weeks (Full ROM and function)}

Advance ROM: Full elbow and forearm ROM out of HEB, Terminal elbow extension performed with the forearm neutral or pronated until 3 months. Initiate elbow and forearm strengthening. Avoid varus forces across the elbow until 3 months postop. Avoid activities creating axial load to involved extremity until 3 months postop.

Indomethacin can be used for 3 weeks following surgery, $25 \mathrm{mg}$ 3 times daily, as prophylaxis against heterotopic ossification in both radial head excision and replacement patients.

\subsection{Follow up}

Patients were followed up for a period of minimum of 1 year every month for 3 months and every 3 months thereafter. Functional assessment was done using Mayo's elbow index score. Complications if any were noted and treated accordingly.

\subsection{Functional Score}

Table 1: Functional Score

\begin{tabular}{|c|c|c|c|}
\hline Function & Points & Definition & Points \\
\hline \multirow{4}{*}{ Pain } & \multirow{4}{*}{45} & None & 45 \\
\hline & & Mild & 30 \\
\hline & & Moderate & 15 \\
\hline & & Severe & 0 \\
\hline \multirow{3}{*}{ Motion } & \multirow{3}{*}{20} & $\operatorname{Arc}>100^{\circ}$ & 20 \\
\hline & & $\operatorname{Arc} 50-100^{\circ}$ & 15 \\
\hline & & $\operatorname{Arc}<50^{\circ}$ & 5 \\
\hline \multirow{3}{*}{ Stability } & \multirow{3}{*}{10} & Stable & 15 \\
\hline & & Moderate instability & 5 \\
\hline & & Gross instability & 0 \\
\hline \multirow{5}{*}{ Function } & \multirow{5}{*}{25} & Comb hair & 5 \\
\hline & & Feed & 5 \\
\hline & & Hygiene & 5 \\
\hline & & Wear shirt & 5 \\
\hline & & Wear shoes & 5 \\
\hline
\end{tabular}

\section{Results}

There were 33 patients with Fracture radial head in our study. $18(54 \%)$ underwent excision arthroplasty and 15(46\%) underwent replacement arthroplasty. The minimum follow up period was 12 months and maximum follow up was for a period of 30 months with mean follow up of 19 months. There were 25 male patients and 8 female patients. 12 male and 6 female patients underwent excision arthroplasty, and 13 male and 2 female patients underwent replacement arthroplasty of radial head (Table 2).

Table 2: Demographic profile

\begin{tabular}{|c|c|c|c|}
\hline Surgery & $\begin{array}{c}\text { Excision } \\
\text { arthroplasty }\end{array}$ & $\begin{array}{c}\text { Replacement } \\
\text { arthroplasty }\end{array}$ & Total \\
\hline Male & $12(36.36 \%)$ & $13(39.39 \%)$ & $25(75.75 \%)$ \\
\hline Female & $6(18.18 \%)$ & $2(6.06 \%)$ & $8(24.25 \%)$ \\
\hline Total & $18(54.55 \%)$ & $15(45.45 \%)$ & $33(100 \%)$ \\
\hline
\end{tabular}

17 patients had Mason type 2 Fractures and 16 patients had mason type 3 fracture. 9 patients from Mason type 2 and 9 patients from Mason type 3 underwent excision arthroplasty. 8 patients from Mason type 2 and 7 patients from Mason type 3 fractures underwent replacement arthroplasty (Table 3).

Table 3: Fracture pattern

\begin{tabular}{|c|c|c|c|}
\hline $\begin{array}{c}\text { Fracture } \\
\text { pattern }\end{array}$ & $\begin{array}{c}\text { Excision } \\
\text { arthroplasty }\end{array}$ & $\begin{array}{c}\text { Replacement } \\
\text { arthroplasty }\end{array}$ & Total \\
\hline Mason 2 & $9(27.27 \%)$ & $8(24.24 \%)$ & $17(51.51 \%)$ \\
\hline Mason 3 & $9(27.27 \%)$ & $7(21.21 \%)$ & $16(48.48 \%)$ \\
\hline Total & $18(54.55 \%)$ & $15(45.45 \%)$ & $33(100 \%)$ \\
\hline
\end{tabular}


16 patients had injury on Right elbow of which 7 underwent excision arthroplasty and 9 underwent replacement arthroplasty. 17 patients had injury on Left elbow of which 11 had excision arthroplasty and 6 had replacement arthroplasty (Table 4).

Table 4: Side fractured

\begin{tabular}{|c|c|c|c|}
\hline Side & $\begin{array}{c}\text { Excision } \\
\text { arthroplasty }\end{array}$ & $\begin{array}{c}\text { Replacement } \\
\text { arthroplasty }\end{array}$ & Total \\
\hline Right & $7(21.21 \%)$ & $9(27.27 \%)$ & $16(48.48 \%)$ \\
\hline Left & $11(33.33 \%)$ & $6(18.18 \%)$ & $17(51.51 \%)$ \\
\hline Total & $18(54.55 \%)$ & $15(45.45 \%)$ & $33(100 \%)$ \\
\hline
\end{tabular}

Mean age of the patient population was 34.39 years, mean age of patients who underwent excision arthroplasty was 34.17 years and that of replacement arthroplasty was 34.66 years. There were 15 patients in the age group of 20-30years(Excision arthroplasty -9 , replacement arthroplasty -6), 9 patients in 30 40 years (EA - 3, RA - 6), 7 patients in $40-50$ years $(\mathrm{EA}-5$, $\mathrm{RA}-2)$ and 2 patients in $50-60$ years age group(EA - 1, RA 1) $(\mathrm{p}=-)($ Table 5).

Table 5: Age group

\begin{tabular}{|c|c|c|c|}
\hline Age group & $\begin{array}{c}\text { Excision } \\
\text { arthroplasty }\end{array}$ & $\begin{array}{c}\text { Replacement } \\
\text { arthroplasty }\end{array}$ & Total \\
\hline $20-30$ years & $9(27.27 \%)$ & $6(18.18 \%)$ & $15(45.45 \%)$ \\
\hline $30-40$ years & $3(9.09 \%)$ & $6(18.18 \%)$ & $9(27.27 \%)$ \\
\hline $40-50$ years & $5(15.15 \%)$ & $2(6.06 \%)$ & $7(21.21 \%)$ \\
\hline $50-60$ years & $1(3.03 \%)$ & $1(3.03 \%)$ & $2(6.06 \%)$ \\
\hline Total & $18(54.55 \%)$ & $15(45.45 \%)$ & $33(100 \%)$ \\
\hline
\end{tabular}

11 patients underwent surgery within 48 hours of injury (EA-7, RA-4), 20 patients between 48-96 hours (9-EA, 11-RA) and 2 patients underwent surgery beyond 96 hours (EA-2) (Table 6).

Table 6: Time interval between injury and surgery

\begin{tabular}{|c|c|c|c|}
\hline $\begin{array}{c}\text { Time interval between } \\
\text { injury and surgery }\end{array}$ & $\begin{array}{c}\text { Excision } \\
\text { arthroplasty }\end{array}$ & $\begin{array}{c}\text { Replacement } \\
\text { arthroplasty }\end{array}$ & Total \\
\hline$<48$ hours & $7(21.21 \%)$ & $4(12.12 \%)$ & $11(33.33 \%)$ \\
\hline $48-96$ hours & $9(27.27 \%)$ & $11(33.33 \%)$ & $20(60.60)$ \\
\hline$>96$ hours & $2(6.06 \%)$ & $0(0 \%)$ & $2(6.06 \%)$ \\
\hline Total & $18(54.55 \%)$ & $15(45.45 \%)$ & $33(100 \%)$ \\
\hline
\end{tabular}

Mean time of return to work was 13.2 weeks in the series however mean time of return to work in excision arthroplasty was 12.83 weeks and that of replacement arthroplasty was 13.7 weeks but there was no statistical difference between the two( $\mathrm{p}=$
0.652). All patients had returned to work by 20 weeks. 17 patients returned to normal work between 8 to 12 weeks (EA 10, RA - 7), 12 returned between 13 to 16 weeks (EA - 6, RA 6) and 4 patients between 17 to 20 weeks (EA - 2, RA - 2) (Table 7).

Table 7: Return to work in weeks

\begin{tabular}{|c|c|c|c|}
\hline $\begin{array}{c}\text { Returned to } \\
\text { works (weeks) }\end{array}$ & $\begin{array}{c}\text { Excision } \\
\text { arthroplasty }\end{array}$ & $\begin{array}{c}\text { Replacement } \\
\text { arthroplasty }\end{array}$ & Total \\
\hline $\mathbf{8 - 1 2}$ & $10(30.30 \%)$ & $7(21.21 \%)$ & $17(51.51 \%)$ \\
\hline $\mathbf{1 3 - 1 6}$ & $6(18.18 \%)$ & $6(18.18 \%)$ & $12(36.36)$ \\
\hline $\mathbf{1 7}-\mathbf{2 0}$ & $2(6.06 \%)$ & $2(6.06 \%)$ & $4(12.12)$ \\
\hline Total & $18(54.55 \%)$ & $15(45.45 \%)$ & $33(100 \%)$ \\
\hline
\end{tabular}

Four $(12.12 \%)$ patients had complications in our series. One $(6.66 \%)$ patient who underwent excision arthroplasty had valgus instability, 3(16.67\%) patients who underwent replacement had complications of infection in one patient and stiffness in 2 patients (Table 8).

Table 8: Complications

\begin{tabular}{|c|c|c|c|}
\hline Complications & $\begin{array}{c}\text { Excision } \\
\text { arthroplasty }\end{array}$ & $\begin{array}{c}\text { Replacement } \\
\text { arthroplasty }\end{array}$ & Total \\
\hline Infection & - & $1(3.03 \%)$ & $1(3.03 \%)$ \\
\hline Stiffness & - & $2(6.06 \%)$ & $2(6.06 \%)$ \\
\hline $\begin{array}{c}\text { Valgus } \\
\text { instability }\end{array}$ & $1(3.03 \%)$ & - & $1(3.03 \%)$ \\
\hline Total & $1(3.03 \%)$ & $3(9.09 \%)$ & $4(12.12 \%)$ \\
\hline
\end{tabular}

The functional assessment was done with Mayo's Elbow Index Score. The mean functional score in Excision arthroplasty was 82.2(SD - 9.11) and that of replacement arthroplasty was 78.3(SD -11.5$)(p=0.453$ as tested by students' $t$ test)(Table 9).

Patients were grouped into 4 categories based on outcomes with Mayo's Elbow index score into excellent, good, fair and poor results. 9 patients had excellent results(EA - 6, RA - 3), 17 patients had good results(EA -9, RA - 8), 6 patients had fair results(EA - 3, RA - 3) and one patient had poor result who had undergone replacement arthroplasty $(\mathrm{p}=0.615$ as assessed by Chisquare test)(Table 10).

Table 9: Mayo's elbow score for surgery

\begin{tabular}{|c|c|c|c|}
\hline Surgery & $\mathbf{N}$ & Mean & Std. deviation \\
\hline Excision arthroplasty & 18 & 82.2222 & 9.11079 \\
\hline Replacement arthroplasty & 15 & 78.3333 & 11.59844 \\
\hline
\end{tabular}

Table 10: Mayo's 4 point scale for surgery

\begin{tabular}{|c|c|c|c|c|c|}
\hline Surgery & Excellent & Good & Fair & Poor & Total \\
\hline Excision arthroplasty & $6(33.3 \%)$ & $9(50.0 \%)$ & $3(16.7 \%)$ & $0(0.0 \%)$ & $18(100.0 \%)$ \\
\hline Replacement arthroplasty & $3(20.0 \%)$ & $8(53.3 \%)$ & $3(20.0 \%)$ & $1(6.7 \%)$ & $15(100.0 \%)$ \\
\hline Total & $9(27.3 \%)$ & $17(51.5 \%)$ & $6(18.2 \%)$ & $1(3.0 \%)$ & $33(100.0 \%)$ \\
\hline
\end{tabular}

\section{Discussion}

Historically, the radial head was believed to be expendable. It is universally appreciated as a vital elbow structure for forearm and elbow stability. Radial head resection overloads the coronoid process, the elbow then depends on the MCL to prevent valgus deformity, if interosseous membrane is disrupted the radius is proximally migrate and for each $\mathrm{mm}$ of radial shortening, the distal ulnar load increases by approximately $10 \%$. Radial head excision has complications of chronic ulnar wrist pain, instability, elbow stiffness, loss of strength, degenerative arthritis, cubitus valgus, heterotopic and Myositis ossificans. Some of these complications were due to biomechanical loss due to radial head excision. Radial head replacement was seen as an alternative treatment to avoid all these complications and better outcomes, however, the optimal management of Mason type II and III fractures of the radial head is controversial and the evidence for it is unclear by the available literature.

Our study was a short term comparative study of functional outcome or radial head excision arthroplasty and radial head replacement arthroplasty. We had 33 patients who had radial head fractures with patients predominantly male and equal 
number of mason type II and III fractures. Left elbow was predominantly affected in our series. The patients were between age of 20 to 60 years with mean age of 34.39 years except two patients who were in 50-60 age group all were below 50 years. The demographic and fracture profile of the patients between the two modalities of treatment were similar and there was no statistically significant difference. There were 18(54.6\%) patients who underwent excision arthroplasty and 15(45.4\%) patients who underwent replacement arthroplasty. Only two patients underwent surgery beyond 96 hours had excision arthroplasty and all other patients underwent surgery before 96 hours. Mean time for return to work was 13.2 weeks in series, however excision arthroplasty patients had mean time for return to work 12.83 weeks and replacement arthroplasty patients 13.7 weeks which was not statistically different. Only one patient with excision arthroplasty had a complication of valgus instability. There were no other complications in patients who underwent excision arthroplasty in our series. There were complications in three patients with replacement arthroplasty, one patient had infection and two patients had stiffness. There were no other complications which were stated in literature.

We assessed the functional outcome using Mayo's Elbow Index Score. The mean functional score was 82.2(SD-9.11) for excision arthroplasty and 78.3(SD-11.5) ( $\mathrm{p}=0.453)$ as assessed by student's t score. There was no significant difference between the two modalities of treatment. When the patients were grouped into categories based on the outcome, $78.8 \%$ of patients had excellent to good results and $18.2 \%$ (6) patients had fair outcome. Only one patient with radial head replacement arthroplasty had poor result. This shows that both modalities had most of patients with excellent to good results and few patients with fair results. The patient who had poor result with radial head replacement arthroplasty had infection as complication. We tried to review the literature with that of our results.

The literature provides limited comparative information regarding between radial head excision arthroplasty and radial head replacement arthroplasty. Due to the difficulty of conducting randomized controlled trials and the relatively small number of radial head fractures seen even in large centers, there is little statistical power to any of the studies included. Throughout the literature there is evidence that both provide satisfactory outcomes. Many of these studies are single-arm studies looking at the functional outcome of resection or replacement alone. The long term success of radial head resection has been shown in some long term studies. However, while some recent articles outline the short term success using radial head replacement, long term data on the outcome of radial head replacement in the current literature is limited. Thus, radial head resection has an advantage over the radial head replacement of proven longevity.

Mehmet Can unlu, in his retrospective multicentric comparitive study of the functional results of radial head resection and prosthesis. 14 irreparable Mason Type-III radial head fracture patients treated with radial head resection $(n=7)$ or radial head prosthesis $(n=7)$ were evaluated with DASH and Mayo Elbow and Wrist scores to determine clinical outcomes. Functional outcomes for resection and prosthesis patients were the following: mean DASH scores, 25.8 and 17.2; mean Mayo Elbow scores, 74 and 84.1; mean Mayo Wrist scores, 84 and 92.5 respectively ${ }^{[12]}$ The results were comparable to that of our study.

Hall et al. have identified a series of patients with postero-lateral rotatory instability following radial head resection [13]. Lindenhovius et al. found that radial head excision had a higher risk of subsequent elbow dislocation and long-term arthrosis compared to open reduction and internal fixation (ORIF) ${ }^{[14]}$. Although, there are some reports stating that most patients with an isolated comminuted fracture of the radial head treated nonoperatively or with a radial head excision report no or only minor long-term complaints ${ }^{[15]}$.

Primary goal in surgical treatment is to restore elbow stability in order to preserve the complex physiologic elbow kinematics. In this respect, medial collateral ligament is the primary constrainer in valgus stress. Radial head contributes secondarily to valgus stability $[9,16]$ and its preservation is mandatory in case of fractures that involve soft tissue and ligaments to avoid chronic instability.

Kaas et al. concluded in his nine retrospective series that there was insufficient evidence as to which method of management of radial head fractures was superior ${ }^{[17]}$.

Janssen et al. performed a long term retrospective study to evaluate the outcome of 21 patients who underwent radial head resection with modified version of the Morrey scoring system to assess the patients. 17 patients followed up at 16-30 years had continued their previous occupation. Only one patient had a poor outcome, having to change his job and his recreational activities because of poor postoperative function. From the data including all 21 patients initially enrolled in this study, 17 scored excellent, 3 good and 1 fair at their most recent evaluation. No patients had symptoms of instability, wrist degeneration, or limited elbow flexion. Eleven patients had mild elbow degeneration, four had on going pain, eight had loss of extension, one had limited pronation and two had limited supination. The authors recommend early resection and mobilization for Mason type III fractures to avoid future functional impairment ${ }^{[18]}$

Iftimie et al. in their long term study of 17 years who underwent radial head resection in 16 patients concluded that radial head resection provides a satisfactory preservation of functional range at the elbow. The mean DASH score was 4.49 and the mean MEPI was 96.8, which were similar to the outcomes of patients undergoing the same treatment for Mason type II fractures. All patients continued with their previous activities ${ }^{[19]}$.

Antuna et al. in their retrospective study with a mean followup of 25 years (minimum 15 years) of 26 patients who were treated with radial head resection for Mason type III fractures in a group of young manual workers in age group of 15-39 years (average age 29 years) assessed elbow function with MEPI and DASH scales and reported a satisfactory functional outcome in $90 \%$ of the patients. Two of the twenty six patients had moderate elbow pain and evidence of instability at the time of last followup. All other patients in this study reported a satisfactory outcome ${ }^{[20]}$. Leppilahti et al. evaluated the outcomes of 23 patients who underwent radial head resection (17 patients - Mason type III fractures and 6 patients - Mason type II fractures) were followed up for 5 years and found to have satisfactory results ${ }^{[21]}$.

Two small cohort studies on radial head replacements for treatment of Mason type III radial head fractures, Smets et al. reported results from their multi-centre trial using a bipolar prosthesis after 25.2 months of average follow-up for 13 Mason type III fractures were managed by radial head replacements. The average age was 46 years (range 20-64 years). Functional outcomes of these 13 patients using the Mayo Elbow Performance Index (MEPI) were evaluated. Their results showed seven excellent, three good, one fair and two poor outcomes. One patient with a poor outcome required removal of prosthesis. Average range of motion at the elbow showed moderate deficits. The authors believed that these results were 
comparable to the successful outcomes presented in several case series of radial head replacements. In our series we had only one poor outcome while all others had fair to excellent results ${ }^{[22]}$. Moro et al, completed a retrospective study of 10 patients with Mason type III fractures treated with radial head replacements over an average of 2 years. The average age was 47 years (range 28-63 years). The study monitored functional outcomes according to the MEPI and the Disability of Arm, Shoulder and Hand (DASH) score. Both assessments compared the function of the injured arm with the contralateral arm. Average grip strength was significantly reduced with an average measurement of $28 \mathrm{~kg}$ compared with $34 \mathrm{~kg}$ in the uninjured arm $(\mathrm{P}<0.05)$. Range of motion was also reduced compared to the uninjured arm. Average pronation was $78^{\circ}$ compared to $79^{\circ}$, supination $69^{\circ}$ compared to $77^{\circ}$, elbow flexion $140^{\circ}$ compared to $143^{\circ}$ and elbow extension deficit was $8^{\circ}$ compared to full extension on the uninjured side $(\mathrm{P}<0.05)$. Hand dominance was not reported. Six patients suffered complications, including elbow stiffness, ulnar nerve dysesthesia, varying levels of heterotopic ossification, one superficial infection and one patient developed a regional sympathetic-mediated pain syndrome. It was noted by the authors that three patients were not able to return to preinjury activities and/or employment, thus accordingly the MEPI had poor outcomes. Some of the poor outcomes documented in this article could be attributed to other concomitant injuries and other comorbid conditions. We did not encounter any complications except for one infection in our series as compared to this study [23]. Popovic et al. evaluated the elbow function and complication rates following 11 Mason type III fractures treated with radial head replacement using the bipolar prosthesis. Average age of the patients was 52 years (range 22-68 years). Based on a modified Morrey Scoring System, four had an excellent outcome, four were good, two were fair and one had a poor outcome at a mean follow-up of 32 months (range 24-56 months). Reported average motion deficits were $10^{\circ}$ of lost flexion, $13.7^{\circ}$ of lost pronation and $16.1^{\circ}$ loss of supination, compared to the uninjured arm. Five of the 11 cases reported mild elbow pain with heavy activity and two reported moderate pain with daily activities. The one poor result was reported in a patient who had sustained other multiple injuries to the affected upper limb. The patient had significantly reduced mobility at the elbow and forearm rotation with associated moderate pain with daily activities ${ }^{[24]}$.

Ashwood et al. published the outcomes of 16 patients with Mason type III fractures treated with a titanium radial head prosthesis over a 5-year period. Average age was 45 years (range 21-72 years). Six of these patients had a delayed replacement with an average of 37 days after injury. All patients were followed up for a mean of 2.8 years clinically and radiographically. Eight patients had excellent outcomes, five were good, three were fair and no cases had a poor outcome. All three fair results occurred in patients who had delayed surgery. The authors concluded that this method of treatment for Mason type III fractures was satisfactory and noted that early mobilization is important for preserving the elbow range of movement and function ${ }^{[25]}$.

Our study is a short term comparative study with small number of patients. The functional results of both modalities of treatment in our study was similar, however there was a case of infection and two cases of stiffness in replacement arthroplasty, and one case of valgus instability in excision arthroplasty. Our study is limited by small number of patients and short term results. Long term results can ascertain which patients will have better functional outcomes in long run.

\section{Conclusion}

Both radial head excision arthroplasty and radial head replacement arthroplasty give good short term outcomes. The radial head excision arthroplasty is simple, easy and cheaper to perform. Long term prospective studies are required to measure outcomes in order to know which is better of two in long run.

\section{Case Illustrations}

\section{Case 1. Radial head excision arthroplasty}
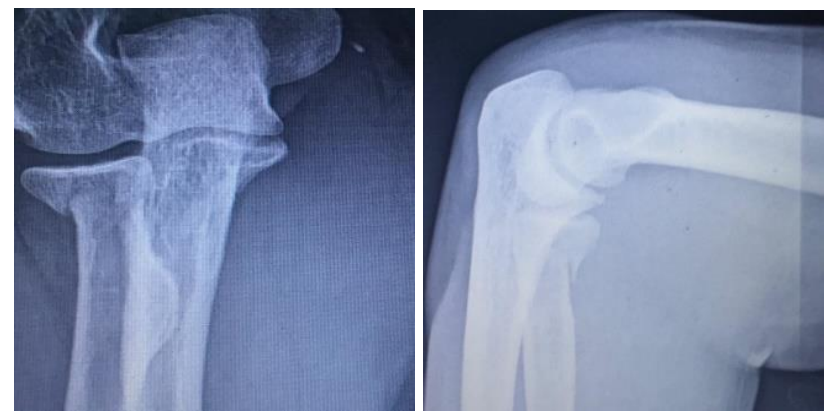

Fig 2a: Pre-op AP \& lateral view of right elbow shows radial head fracture
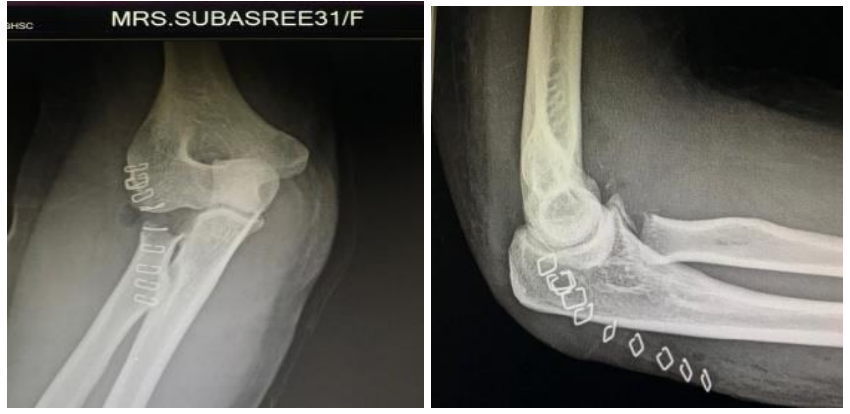

Fig 2b: Post op AP and lateral view of right elbow shows radial head excision

\section{Case 2}

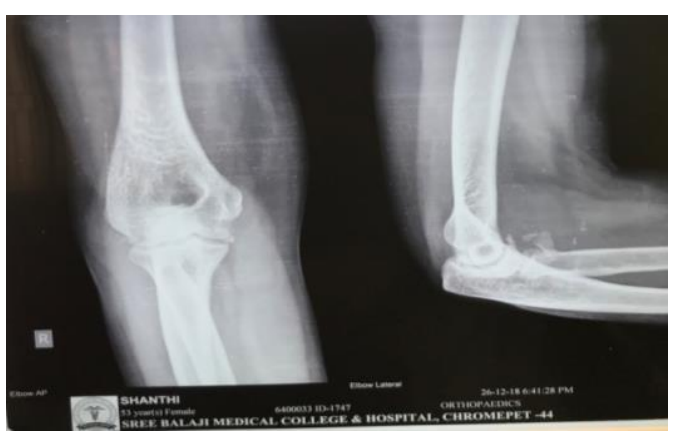

Fig 3a: Pre op AP and lateral view of right elbow shows radial head fracture

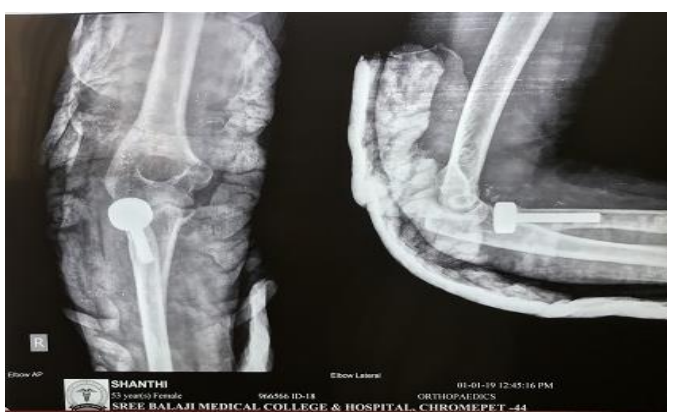

Fig 3b: Anteroposterior and lateral view of right elbow shows radial head replacement 


\section{Clinical pictures}

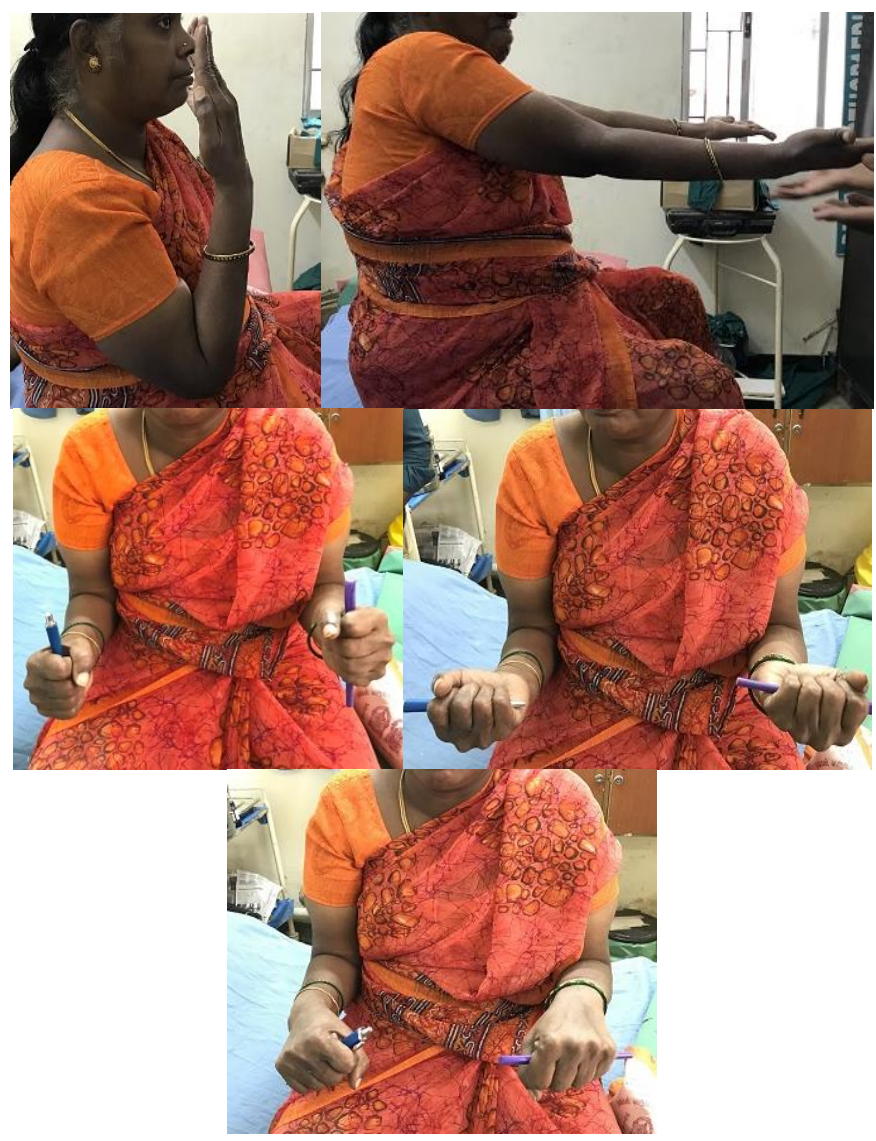

Fig 4: Patient showing full flexion, full extension, neutral, supination and pronation after 6 weeks of radial head replacement.

\section{Reference}

1. Pappas N, Bernstein J. Fractures in Brief: Radial Head Fractures. Clinical Orthopaedics and Related Research, 2010; 468(3):914-916.

2. Shariff Z, Patel KJ, Elbo A, Guisasola I. Bilateral Radial Head Fractures in a Woman with Trivial Trauma. Medscape General Medicine. 2005; 7(3):8.

3. Karlsson KM, Herbertsson P, Nordqvist A, Besjakov J, Josefsson OP, Hasserius R. Comminuted fractures of the radial head, Favourable outcome after 15-25 years of follow up in 19 patients. Acta Orthop. 2010; 81(2):224-27.

4. Mason ML. Some observations on fracture of the head of the radius with a review of one hundred cases. Br J Surg. 1954; 42:123-32.

5. Van Riet RP. Associated injuries complicating radial head fractures: a demographic study, Clinical Orthopaedics and Related Research, 2005.

6. Hilgersom NF, Eygendaal D, van den Bekerom MP. "Is radial head resection the first choice treatment of comminuted radial head fractures without associated instability? Injury. 2017; 48(2):560-562.

7. Itamura J, Roidis N, Mirzayan R, Vaishnav S, Learch T, Shean C. Radial head fractures: MRI evaluation of associated injuries, Journal of Shoulder and Elbow Surgery. 2005; 14(4):421-424.

8. McGinley JC, Gold G, Cheung E, Yao J. MRI Detection of Forearm Soft Tissue Injuries with Radial Head Fractures, HAND. 2014; 9(1):87-92.

9. Morrey BF, an KN, Stormont TJ. Force transmission through the radial head. The Journal of Bone \& Joint Surgery. 1988; 70(2):250-256.
10. Jensen SL, Olsen BS, Tyrdal S, Søjbjerg JO, Sneppen O. Elbow joint laxity after experimental radial head excision and lateral collateral ligament rupture: Efficacy of prosthetic replacement and ligament repair, Journal of Shoulder and Elbow Surgery. 2005; 14(1):78-84.

11. McGinley JC, Roach N, Hopgood BC, Limmer K, Kozin $\mathrm{SH}$. Forearm interosseous membrane trauma: MRI diagnostic criteria and injury patterns. Skeletal Radiol. 2006; 35:275-281.

12. Comparison of the functional results of radial head resection and prosthesis for irreparable mason type-III fracture Mehmet Can Ünlü, M.D, Mehmet Fatih Güven, M.D, Lercan Arslan, M.D.,1 Önder Aydıngöz, M.D.,1 Mustafa Gökhan Bilgili, M.D.,2 Alkan Bayrak, M.D.,2 Muharrem Babacan, M.D.,1 Gökhan Kaynak, M.D.,1 Hüseyin Botanlıoğlu, M.D.1

13. Hall JA, McKee. Postero-lateral rotatory instability of the elbow following radial head resection. J Bone Joint Surg Am. 2005; 87:1571-1579

14. Lindenhovius AL, Felsch Q, Doornberg JN et al. Open reduction and internal fixation compared with excision for unstable displaced fractures of the radial head. J Hand Surg Am. 2007; 32(5):630-636.

15. Karlsson MK, Herbertsson $\mathrm{P}$, Nordqvist $\mathrm{A}$ et al. Comminuted fractures of the radial head. Acta Orthop. 2010; 81(2):226-229

16. Mahmoud SS, Moideen AN, Kotwal R, Mohanty K. Management of mason type 1 radial head fractures: a regional survey and a review of literature. Eur J Orthop Surg Traumatol. 2014; 24(7):1133-37.

17. Kaas L, Struijs PA, Ring D, van Dijk CN, Eygendaal D. Treatment of Mason type II radial head fractures without associated fractures or elbow dislocation: a systematic review. J Hand Surg Am. 2012; 37(7):1416-21.

18. Janssen RP, Vegter J. Resection of the radial head after Mason type-III fractures of the elbow: Follow-up at 16 to 30 years. J Bone Joint Surg Br. 1998; 80:231-3.

19. Iftimie PP, Calmet Garcia J, de Loyola Garcia Forcada I, Gonzalez Pedrouzo JE, Gine Goma J. Resection arthroplasty for radial head fractures: Long term follow-up. J Shoulder Elbow Surg. 2011; 20:45-50.

20. Anturia SA, Sanchez-Marquez JM. Long term results of radial head resection following isolated radial head fractures in patients younger than forty years old. J Bone Joint Surg Am. 2010; 92:558-66

21. Leppilahti J, Jalovaara P. Early excision of the radial head for fracture. Int Orthop. 2000; 24:160-2.

22. Smets S, Govaers K, Jansen N, Van Riet R, Schaap M, Van Glabbeek F. The floating radial head prosthesis for comminuted radial head fractures: A multicentric study. Acta Orthop Belg. 2000; 66:353-8.

23. Moro JK, Werier J, MacDermid JC, Patterson SD, King GJ. Arthroplasty with metal radial head for unreconstructible fractures of the radial head. J Bone Joint Surg Am. 2001; 83:1201-11.

24. Popovic N, Gillet P, Rodriquez A, Lemaire R. Fracture of the radial head with associated elbow dislocation: Results of treatment using a floating radial head prosthesis. J Orthop Trauma. 2000; 14:171-7.

25. Ashwood N, Bain GI, Unni R. Management of Mason type-III radial head fractures with a titanium prosthesis, ligament repair and early mobilization. J Bo ne Joint Surg Am. 2004; 86:274-80. 